\title{
Perceived Stress of Pakistani Parents Having Normal Children Aged Under Ten Visiting a Tertiary Care Hospital in Lahore, Pakistan
}

${ }^{1}$ Saadia Shahzad, ${ }^{2}$ Rosheen Zahid, ${ }^{3}$ Bushra Rehman, ${ }^{4}$ Tahseen Haider Kazmi

${ }^{1}$ Department of Community Medicine, Shalamar Medical and Dental College, Lahore

${ }^{2}$ Department of Surgery, Shalamar Medical and Dental College, Lahore

${ }^{3}$ Department of ENT, Shalamar Medical and Dental College, Lahore

${ }^{4}$ Department of Community Medicine, Shalamar Medical and Dental College, Lahore

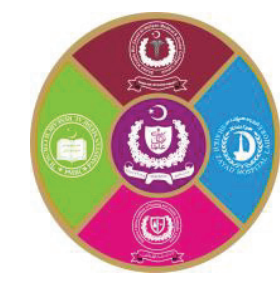

\begin{abstract}
Introduction: Having children changes the dynamics of family functioning and parenting role can become a source of stress for parents, even if their child is following a normal growth pattern without any unusual problem. A maximal number of studies in our setup have been conducted to assess stress levels in parents who have differently abled (special needs) children. This study, in contrast, will assess the perceived stress level in parents who have normal children following a normal growth pattern. Aims \& Objectives: 1) To determine perceived stress levels in parents having normal children $\leq 10$ years of age. 2) To identify the association of perceived stress levels in parents with socio-demographic factors. Place and duration of study: Shalamar Hospital, Dec 18, 2019-Mar 19, 2020. Material \& Methods: A cross-sectional study was conducted in one tertiary level hospital in Lahore. The study subjects were parents with normal children $\leq 10$ years of age. Purposive sampling technique was applied to recruit the subjects. Study variables were: a) sociodemographic b) variables of perceived stress among parents. Data was collected upon the Perceived Stress Scale (PSS), and a structured socio-demographic Performa. Data was analyzed using SPSS 20, with perceived stress as the outcome. Descriptive statistics were calculated, while the Independent Samples T-test was used to test differences between PSS scores and characteristics of the family. Multivariable Logistic Regression model was applied for studying associations of perceived stress with socio-demographic characteristics. Results: From a total of 390 respondents, the mean parental perceived stress score was $41.59 \pm 8.27$. Among these, $32.6 \%$ were categorized in low stress, $50.8 \%$ moderate, and $16.6 \%$ in high stress category. A significant association was found between perceived stress and the working status of the mother (pvalue $=0.011$ ), and with the father's monthly income ( $p$-value $=0.000)$. The Independent sample t-test showed significant differences between PSS total score and structural types of the family ( $p$-value $=0.001$ ). Conclusion: The development of a child with parents' positive mental health is important, and parental stress compromises the healthy growth of children. The current results warrant further study at a community level with a representative sample to have a more in-depth analysis of the application of some intervention at an early stage. This will assist in minimizing parental stress and improve parenting quality.
\end{abstract}

Keywords: Perceived Parental Stress, $\leq 10$-year-old, typical children

\section{INTRODUCTION}

$\mathrm{T}$ ypical/ normal by the dictionary means; being of the same sort or kind that is conventionally expected as usual. Typical growth of a child or typical child thus implies that he/she is showing all important traits of a type, class, or group. Similarly, the normal growth of a child or a normal child implies that he/she lacks deviation from the usual/ expected conventional norms. ${ }^{1}$ Parenting stress according to literature refers to the intensity and relative magnitude of stresses that exist in the parent-child relationship. ${ }^{2}$ Literature search has revealed the fact that having children naturally changes the dynamics of family function. Thus parental role could be a source of stress for many parents. ${ }^{3}$ Many studies have revealed that the demands and responsibilities that are associated with raising and caring for children are stressful for both parents. ${ }^{4}$ Studies also reveal that both mothers and fathers have reported perceiving stress differently. 
Literature shows that techniques of coping and social support could help people to face stress. However, it was found that gender affected how people evaluate, perceive, and respond to stressors. $^{7,8}$ Literature shows that mothers as compared to fathers perceive more parenting stress and depression. Although over the period the rate of father's involvement in parenting has increased; mothers still have the major part of parenting thus feel more stressed out. Especially mothers with fiveyear-old children get distressed upon their child's school adjustment shortly . ${ }^{2}$

Most reviewed research articles that investigated parental stress when parents have children with some congenital disorder e.g. Autism, developmental delays, cerebral palsy, etc..$^{9,10,11}$ However, very few studies have examined the stress level in parents having normal children. Parental stress prevalence in parents having children with Autism was found to be $47.4 \%$ in fathers, and $52.6 \%$ in mothers. ${ }^{12}$ Another study conducted in Jordan to assess parental stress level among parents with normal children have found a significant difference in stress levels between fathers and mothers; with mothers having significantly higher scores. The mean stress score for mothers was 17.94 \pm 6.41 , compared with $15.13 \pm 7.12$ for fathers. ${ }^{13}$ In a study various factors were reported to be predictors of parental stress like disability in a child, gender of a parent, socioeconomic status, number of children, years married, age of parents and age of the child, and parent's social support network..$^{14}$

Researchers believe that parental stress is assumed to be at a higher side in developing countries like Pakistan as compared to developed countries. This phenomenon is probably due to various influencing factors that play a key role in this situation like social set up, cultural values, societal norms, family system, socioeconomic status, lack of resources, low literacy rate, lack of awareness regarding good parenting techniques, and overt use of social media by the children. A literature search could not find any such study conducted in Pakistan to date. There is very limited information in our setup about the magnitude of parental stress among parents having healthy children $<10$ years of age. Likewise, awareness regarding coping techniques for parental stress in a positive manner is also grossly lacking among parents in our setup. Social issues must be looked into in detail to have a better quality of life. Moreover, this study is very significant as to the maximum knowledge of the researcher this study is the first of its kind conducted in our Pakistani society; as most of the studies had been done to assess stress among parents with physically challenged children. The fact that stress among parents who are raising normal children must be taken into account as it affects their mental health as well as their parenting quality.

Objectives of the study are 1) to determine perceived stress levels in parents having typical children $\leq 10$ years of age 2) to identify the association of perceived stress levels in parents with socio-demographic factors.

\section{MATERIAL AND METHODS}

It was a cross-sectional study conducted in the Pediatric Out-Patient Department of the Shalamar Hospital, Lahore; in three months (Dec 18, 2019Mar 19, 2020).

The sample size of 390 was calculated using Open Epi software with an assumed prevalence of $50 \%$, \&a margin of error of $5 \%$. Our study subjects were parents visiting the outpatient department; \&purposive sampling technique was applied to select the study participants.

The inclusion criteria were: 1) willingness of the respondent parents 2) parents having normal children $\leq 10$ years of age. The exclusion criteria: 1) parents having a child with any congenital abnormality. Study variables were: a) Sociodemographic variables of parents b) Variables of parental stress.

Data was collected upon the questionnaire after taking informed consent from the respondent.

To measure parental stress, the Perceived Stress Scale (PSS) from the State of New Hampshire Employee Assistance Program was used; which is available in free access at info@mindgarden.com. Cut-offs for the PSS were 0-13 considered as a lowstress category, 14-26 as moderate stress, and 27-40 considered as a high-stress category. The total score for perceived stress was taken as an outcome.

All ethical considerations were duly considered and observed during the study; and participants were assured of the confidentiality of the data. Institutional Review Board certification was acquired from the Ethical Board of the Shalamar Institute of Health Sciences, Lahore, before the start of the study.

\section{Statistical analysis:}

Descriptive stats, mean $\pm \mathrm{SD}$, frequency trends, \& percentages for categorical factors were calculated. Multivariable Logistic Regression was applied to determine the association of perceived stress with sociodemographic factors, comparing moderate to high stress against the low-stress category. Independent Samples T-test was used to test 
differences between PSS scores and characteristics of the family; \& p-value of $<0.05$ was considered significant.

\section{RESULTS}

Data of 390 parents were entered and analyzed via SPSS 20. There were $59(15.1 \%)$ fathers and 331 $(84.9 \%)$ mothers in the research. The mean age was $28.99 \pm 4.55$. The mean stress score for respondents was $18.03 \pm 8.8$.

Table-1 shows the socio-demographic profile of the recruited subjects. The majority of the respondents were educated, with about $40 \%$ having an education of intermediate and above. Most respondents reported having less than 4 children in their household. More than $70 \%$ of subjects had their family income less than PKR 50,000.

\begin{tabular}{|c|l|c|}
\hline S. No & \multicolumn{1}{|c|}{ Variable } & n (\%) \\
\hline 1. & Father Education & $240(61.5 \%)$ \\
& Class 1-10 & $150(38.4 \%)$ \\
\hline 2. & Intermediate and above & \\
& Mother Education & $233(59.8 \%)$ \\
& Class 1-10 & $157(40.2 \%)$ \\
\hline 3. & Intermediate and above & $343(88 \%)$ \\
& $1-3$ & $47(12 \%)$ \\
\hline 4. & Number of children & $102(26.2 \%)$ \\
& Nupe of family structure & $288(73.8 \%)$ \\
\hline 5. & Joint & House status \\
& Rented & $86(22.1 \%)$ \\
& Own & $304(77.9 \%)$ \\
\hline 6. & Monthly income of the & $285(73.07 \%)$ \\
& father & $97(24.87 \%)$ \\
& Up to PKR 50000 & \\
\hline & $>$ PKR 50000 & \\
\hline
\end{tabular}

Table-1: Socio-demographic profile of the respondents $(n=390)$

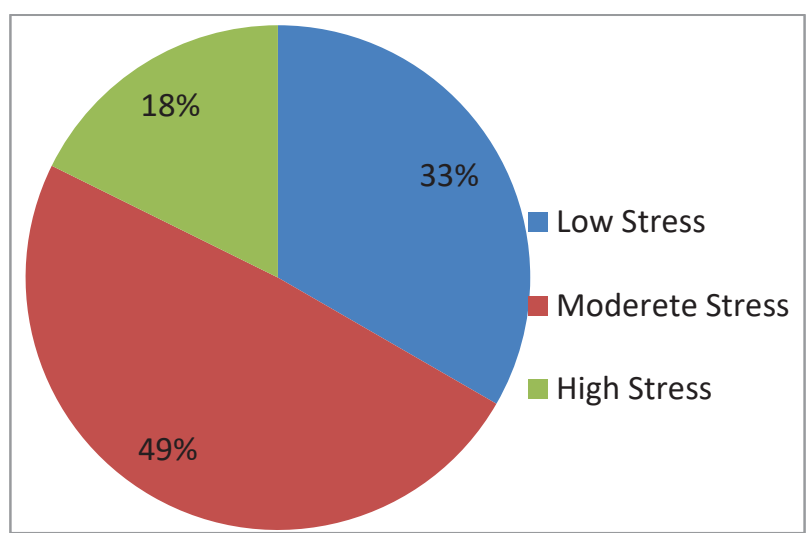

Fig-1: Categorization of Perceived Stress among both parents $(n=390)$
Fig-1 shows the categorization of stress scores among responding parents. The figure shows that $49 \%$ of respondents had moderate stress levels, followed by $33 \%$ in the low category. High-stress scores were obtained from among $18 \%$ of the subjects.

Table-2 shows the logistic regression analysis of stress with family characteristics. The working status of the mother and the family's monthly income was significantly associated with perceived stress in the final adjusted model; the working status of mothers increases stress by 4 times [OR 4.12 (95\% CI: 1.39-12.25)].

\begin{tabular}{|c|c|c|c|c|}
\hline Variables & \begin{tabular}{|c|} 
Univariate \\
analysis \\
OR(95\% CI $)$ \\
\end{tabular} & P-value & $\begin{array}{c}\text { Multivariate } \\
\text { analysis } \\
\text { OR(95\%CI) }\end{array}$ & P-value \\
\hline \begin{tabular}{|l} 
Total \\
number of \\
children
\end{tabular} & $\begin{array}{c}1.250 \\
(1.019-1.533)\end{array}$ & $0.033^{*}$ & $\begin{array}{c}1.218 \\
(0.978-1.516)\end{array}$ & 0.078 \\
\hline $\begin{array}{l}\text { House type } \\
\text { Own: } \\
\text { Rented: }\end{array}$ & $\begin{array}{l}1 \\
1.730 \\
(1.003-2.984)\end{array}$ & $0.049^{*}$ & $\begin{array}{c}1.380 \\
(0.777-2.451)\end{array}$ & 0.272 \\
\hline \begin{tabular}{|l|} 
Status of \\
mother \\
House wife: \\
Working:
\end{tabular} & $: \begin{array}{l}1 \\
4.018 \\
(1.537-10.500)\end{array}$ & $0.005^{*}$ & $\begin{array}{c}4.120 \\
(1.386-12.248)\end{array}$ & $0.011^{*}$ \\
\hline $\begin{array}{l}\text { Frequent } \\
\text { job changes } \\
\text { by father } \\
\text { No: } \\
\text { Yes: }\end{array}$ & $\begin{array}{l}\mid \\
1 \\
3.072 \\
(1.039-9.079) \\
\end{array}$ & $0.042^{*}$ & $\begin{array}{c}1.578(0.501- \\
4.974)\end{array}$ & 0.436 \\
\hline $\begin{array}{l}\text { Monthly } \\
\text { income }\end{array}$ & $\begin{array}{l}0.626 \\
(0.505-0.777)\end{array}$ & $0.000^{*}$ & $\begin{array}{c}0.653 \\
(0.524-0.815)\end{array}$ & $<.001^{*}$ \\
\hline $\begin{array}{l}\text { Age of } \\
\text { mother }\end{array}$ & $\begin{array}{l}0.977 \\
(0.933-1.023)\end{array}$ & 0.326 & - & \\
\hline $\begin{array}{l}\text { Age of } \\
\text { father }\end{array}$ & $\begin{array}{l}0.991 \\
(0.954-1.030)\end{array}$ & 0.651 & - & \\
\hline $\begin{array}{l}\text { Gender } \\
\text { Male: } \\
\text { Female: }\end{array}$ & \begin{tabular}{|l|}
1 \\
1.456 \\
$(0.824-2.570)$
\end{tabular} & 0.196 & - & \\
\hline $\begin{array}{l}\text { Familytype } \\
\text { Joint: } \\
\text { Nuclear: }\end{array}$ & $\mid \begin{array}{l}1 \\
0.736 \\
(0.449-1.205)\end{array}$ & 0.223 & - & \\
\hline
\end{tabular}

Table- 3 shows the analysis of the differences of PSS scores with family structure type and gender. This shows that scores for joint family structures were found to significantly high compared to nuclear families (p-value 0.001). 


\begin{tabular}{|l|c|c|c|}
\hline \multicolumn{1}{|c|}{ Variable } & $\begin{array}{c}\text { PSS mean } \\
\text { score }\end{array}$ & \pm SD & P-value \\
\hline Type of family & 40.287 & 7.75 & $0.001^{*}$ \\
Nuclear: & 43.187 & 8.63 & \\
Joint: & 42.58 & 8.28 & 0.151 \\
\hline Gender & 41.21 & 8.25 & \\
Male: & \multicolumn{3}{|c|}{ P-value $<.05$ significant } \\
Female: & \multicolumn{2}{|c|}{ P-vere }
\end{tabular}

Table-3: Differences across PSS Total score with Type of Family and Gender

\section{DISCUSSION}

In the past, research defines parental stress as a mismatch between perceptions of environmental demands and personal resources. ${ }^{6}$ Furthermore, previous studies have found that mothers and fathers report perceiving stress differently. ${ }^{5}$

Our study found a higher frequency trend of perceived stress total score among both parents, the maximum range is around 40 , and its mean score being $18.03 \pm 8.8$. Categorical breakdown of the perceived stress total score revealed $33 \%$ in lowstress category, $49 \%$ in moderate, and $18 \%$ as high category stress level. This finding is strongly supported by another study that reported mothers had higher stress as compared to fathers. ${ }^{13}$ Literature search revealed that very few numbers studies had been done to study perceived stress among parents having normal children and the majority of studies were conducted to study stress levels among parents having children with special needs. The frequency of engagement with children was found to be related to the mother's parenting stress as compared to the father's parenting stress. ${ }^{15}$

Our study also suggests that a greater number of mothers and fathers (40.2\% and $38.4 \%$ respectively) had a decent education level (intermediate and above); yet they perceived stress scores were high suggesting that their difficulty in coping with demands and resources. The working status of mothers and family income might be the main influencing factors of their incapability towards coping. The total number of children in the family may be another important factor in this context for higher parental stress. This finding is corroborated in other studies as well. ${ }^{16}$

Compromised economic status might contribute further to parental stress and our study findings show that majority of respondents had an income of less than PKR 50,000. This finding is strongly supported by another study that has linked accessibility to socio-economic resources and economic strain to an appraisal of stress. $^{17}$ Contemporary norms of fatherhood emphasize the dual demands of bread-winning plus daily involvement with children. The results of recent qualitative research show that it is difficult for working-class fathers to meet the demands of quality parenting. Furthermore, on account of job instability and workplace inflexibility, this may increase. ${ }^{15}$ Additionally, joint family structures can further aggravate the perceived stress among individuals. Our study indicates scores to be higher among joint families, however, the multivariable model showed this to be non-significant.

There are limitations to this research. Foremost, the study being cross-sectional, we cannot suggest causality of the above-mentioned factors with perceived stress among parents. Second, the sample size drawn from the target population might not be representative as the subjects were conveniently selected from a single hospital in Lahore. But the study does add an important finding that stress is ubiquitous among most families and a study from the community level with an expanded sample size might provide more in-depth knowledge for stress scores among parents. Moreover, culturally, the role of grandparents might be another important factor to influence stress among parents that was not explored in this research. Literature suggests that grandparents are found to be a likely source of support for many parents, providing emotional, financial, and instrumental assistance. ${ }^{18}$ Future studies could explore that relationship in detail.

\section{CONCLUSION}

The study suggests that parents of normal children are afflicted with moderate to a high category of stress. The working status of mothers and family's income are significant influencers of perceived stress among parents. To raise children with positive mental health, parents themselves must have a positive and stress-free mental state, and measures are needed to assist such families as much as possible. Community counseling is one of the many measures that can be opted for a level of the community, assisting to minimize stress so that parents may provide good quality parenting for their children.

\section{REFERENCES}

1. Definition of Typical/ Normal. Available at: http://www.merriam-webster.com/dictionary visited on 23.6.19.

2. Kim KE, Choi JH. Sources of parenting stress for mothers and fathers of young children. IJST $2015 ; 8(35): 1-8$. 
3. Soltanifar A, Akbarzadeh F, Moharreri F, Ebrahimi A, Mokhber N, et al. Comparison of parental stress among mothers and fathers of children with an autistic spectrum disorder in Iran. Iran J Nurs Midwifery Res 2015; 20(1): 93-98.

4. Cohen S, Janicki DD, Miller GE. Psychological stress and disease. JAMA.2007;298(14):1685-87

5. Masa'Deh R, Collier J, Hall C, Alhalaiqa F. Predictors of the stress of parents of a child with cancer: A Jordanian Perspective. Glob J Health Sci. 2013; 5(6):81.

6. Pelchat D, Lefebvre H, Levert MJ. Gender differences and similarities in the experience of parenting a child with a health problem: current state of knowledge. J Child Health Care 2007; 11(2):112-131.

7. Lazarus RS. Stress and Emotion: A New Synthesis: New York: Springer Publishing Company. 2006; 342.

8. Eaton RJ, Bradley G. The Role of Gender and Negative Affectivity in Stressor Appraisal and Coping Selection. Int J Stress Manag 2008; 15(1):94-115.

9. Sipal RF, Schuengel C, Voorman JM, Van Eck J, Becher G. Course of behavioral problems of children with cerebral palsy: the role of parental stress and support. Child Care Health Dev. 2010; 36(1):74-84.

10. Moh TA, Magiati I. Factors associated with parental stress and satisfaction during the process of diagnosis of children with Autism Spectrum Disorders. Res in Autism SpectrDisord. 2012; 6(1):293-303.

11. Neece CL. Mindfulness-Based Stress Reduction for Parents of Young Children with Developmental Delays: Implications for Parental Mental Health and Child Behavior Problems. J Appl Res Intellect Disabil. 2014; 27(2):174-186.

12. Al Farsi OA, Al Farsi YM, Al Sharbatti MM, Al Adawi S. Stress, anxiety, and depression among parents of children with an autism spectrum disorder in Oman: a case-control study. Neuropsychiatr Dis Treat 2016; 12:1943.

13. Masa-Deh R, Bawadi H, Saifan A, AbuRuz M. Perceived stress of Jordanian parents: A comparative study between mothers and fathers. J NursEduPract. 2015; 5(11): 89-95.

14. Abiding RR. Parenting Stress Index. Charlottesville, VA: Pediatric Psychology Press 1990.

15. Nomaguchi K, Johnson W. Parenting stress among low-income and working-class fathers: The role of employment. J Fam Issues 2016; 37(11): 1535-1557.

16. Kins JR, Marcenko MO. Parenting stress among child welfare involved families: Differences by child placement. Child Youth Serv Rev 2014; 46:19-27.

17. Lewis $M$, Weinraub $M$. The father's role in child development. NY: John Wiley \& Sons. 2010: 157-184.

18. Barth R. Social support networks: Informal helping in human services. Social Support Networks in Services for Adolescents and their Families. 1983: 299-330.

\section{The Authors:}

Dr. Saadia Shahzad

Assistant Professor,

Department of Community Medicine,

Shalamar Medical and Dental College, Lahore.

Dr. Rosheen Zahid

House Officer,

Department of Surgery,

Shalamar Medical and Dental College, Lahore.

Dr. Bushra Rehman

House Officer,

Department of ENT,

Shalamar Medical and Dental College, Lahore.

Prof. Tahseen Haider Kazmi

Department of Community Medicine,

Shalamar Medical and Dental College, Lahore.

\section{Corresponding Author:}

Dr. Saadia Shahzad

Assistant Professor,

Department of Community Medicine,

Shalamar Medical and Dental College, Lahore.

E-mail: saadiazahur@live.com 